BUSINESS

\title{
The carbon cycle ride
}

\section{Carbon offset schemes in developing countries may be finding their feet after a rocky start, as Paroma Basu reports.}

ndia's blooming carbon market has emerged as the hottest destination for companies in the industrialized world seeking to do their bit in the fight against global warming.

But as one of the first nations to move aggressively into carbon trading, India has also been the first to collide with the teething troubles of the fledgling market.

"There is a problem with the process of the Clean Development Mechanism (CDM) itself that no one has been able to remove," says Chandra Bhushan, associate director of the Centre for Science and Environment in New Delhi. "Independent oversight, to ensure that the processes are clean, just isn't there yet."

The CDM was established under the auspices of the United Nations Framework Convention on Climate Change. It lets nations buy certified emissions reductions, or 'carbon credits', from countries that earn them by cutting greenhouse-gas emissions.

Several issues lie at the heart of India's troubles with carbon commerce. They include the country's lack of preparedness, the United Nation's inexperience with the market, the technical difficulties of managing, supervising and regulating projects, and delays in the Kyoto Protocol coming into effect.

Despite the early setbacks, observers say that a solid system of checks and balances is now coming into place. "Because India was and currently is the CDM leader, it is natural that the problems were first faced by Indian projects," says José Domingos Miguez, an official in Brazil's Ministry of Science and Technology and a member and former chair of the CDM's executive board, which oversees the mechanism. "This is a learning-by-doing process."

India is home to 282 of the world's 803 registered carbon-trading projects, according to the United Nations - more than China (116) and India (108) combined. And analysts say that Indian companies have already earned about US\$350 million from these ventures. With another 435 projects in the pipeline, the earnings will quickly run into billions of dollars.

Some claim that the offsetting mechanism is susceptible to easy fraud, but Indian firms counter that they have to jump through several regulatory hoops to gain registration. Under the Marrakech Accords of 2001, which fleshed out the rules for meeting Kyoto targets, projects must clear three stages of review - a process that generally takes about a year to complete.

Once a firm identifies a way to reduce emissions in its business - by switching to wind power, for example - it has to clear its idea with a government task force appointed inside each nation. Then, the projects are audited by UN-accredited 'designated operational entities', which check their methodology, documentation, finances and eligibility. Around six such entities operate in India.

In the third stage, the CDM's executive board, comprising senior climate scientists and officials from around the world, makes the final call. Projects that get the green light can finalize deals with buyers in developed nations. For the rest of the project's duration, $\mathrm{UN}$-appointed auditors visit at regular intervals, awarding credits on the basis of the extent of reductions made.

\section{Delayed take-off}

Just after Marrakech, Indian companies were among the first to propose eligible projects. But the CDM board, established in 2001, didn't actually start operating properly until the Kyoto Protocol went into force, in February 2005. Even then, Miguez says, it was almost a year before the cash and people were available to monitor projects on the ground adequately.

That meant that scores of Indian firms, which filed more than 100 applications before 2005, moved headlong into the process in the absence of clear guidelines. "Everything was a confusion to begin with," recalls Subhash Rastogi, vicepresident for environment, health and safety at the multi-product firm ITC in Kolkata, which moved into the carbon market in 2003 and has since registered seven projects.

Soon, the Indian carbon market began to rack up bad publicity. Questions surfaced about the legitimacy of its projects and the competence of the auditing firms appointed to oversee them. Pressure groups such as the Center for Science and Environment criticized the wrongful approval of undeserving projects.

In particular, a rule agreed at Marrakech allowed for the automatic registration of a project unless at least three board members request to review it within 4-8 weeks. "Some of the projects were going through the automatic

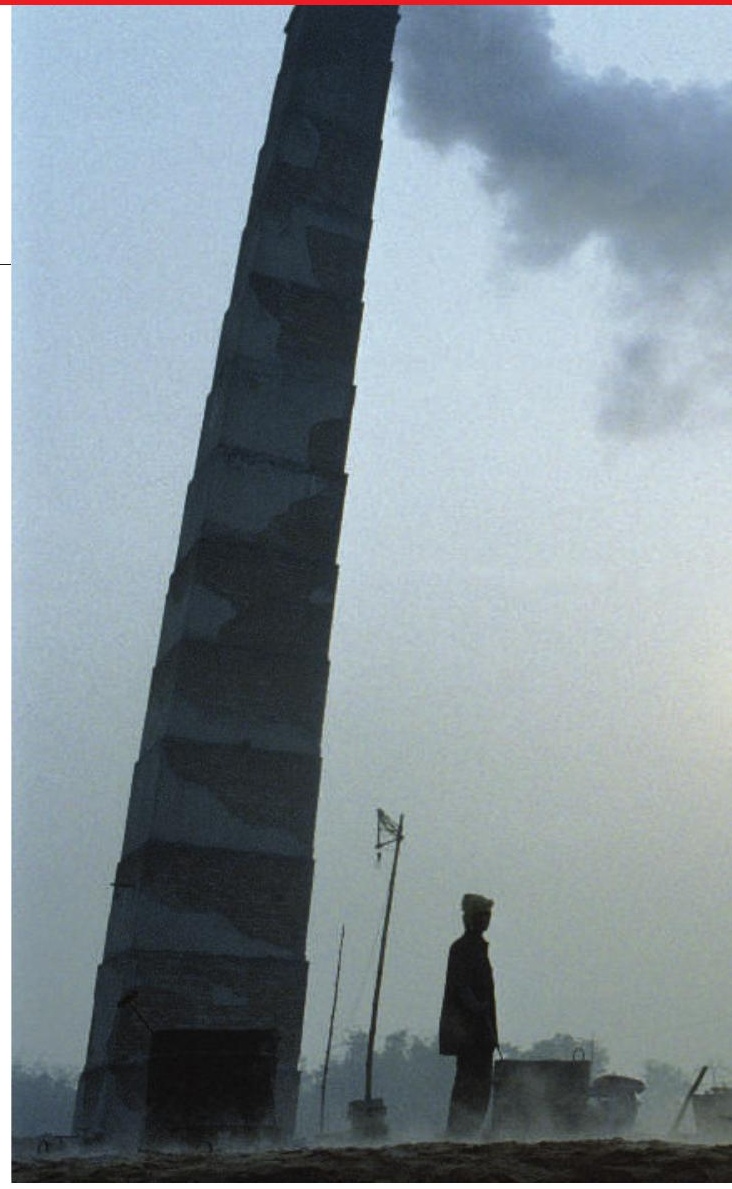

Carbon credits provide incentives for facilities such as this brick factory in Lalgola, India to cut their greenhouse-gas emissions.

mode and getting registered easily," says Rajesh Kumar Sethi, vice-chair of the CDM board and director of the climate-change department in India's Ministry of Environment and Forests. "The CDM secretariat was thinly staffed at the time - but those types of projects are very rare now."

The secretariat, based in Bonn, Germany, now has a technical staff of about 100 to support the 20 board members, Sethi says. The board undertook three random spot-checks last year to keep tabs on national performance, Miguez adds, and it has been updating documentation requirements to tighten up the process.

\section{Measure of doubt}

An obvious problem, however, is the calculation of greenhouse-gas reductions for specific technologies. These calculations require a baseline from which to measure - but that has been tough to establish in several industry sectors, such as aluminium, cement and agriculture.

Another issue is the mechanism's crucial 'additionality' requirement, which holds that to be eligible for benefits, a project has to show that it is genuinely reducing emissions by more than it would have done otherwise. "Additionality is subjective," says Sethi. "Somebody may say it's additional while somebody else may say that it's not."

That murkiness is creating situations in 


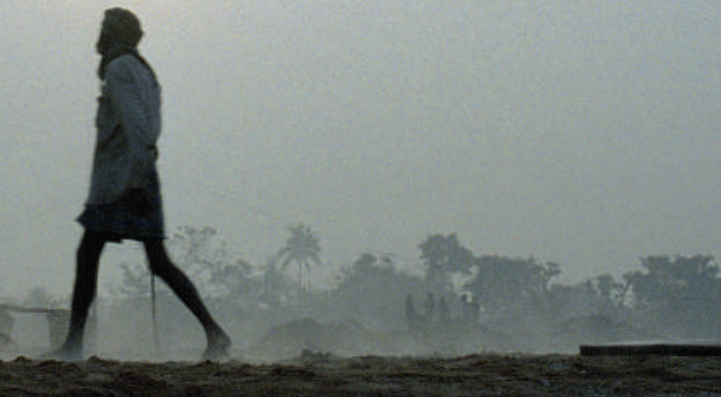

which some companies think that their projects have been rejected unfairly. "A certain randomness persists at the level of the executive board," says Suresh Iyer, deputy general manager of JSW Steel in Mumbai, which has won the world's largest credit award for any one project, for fuel-replacement at its steel mills. "There is no forum in which companies can defend their projects directly in front of the board."

"The feeling of rejection is worse when you don't know the reason," says a high-level executive at a leading cement company who didn't want to be named. "We applied for two projects with exactly the same methodology. Only one got accepted - although the rejected one is a much stronger case." Of 36 projects that the CDM board has rejected so far, 14 are from India.

"The secretariat is still not resourced adequately, either in numbers or expertise," says Paravastu Rambabu, managing director of Indian operations for the consulting firm Cantor CO2E. He adds that auditing companies face similar capacity constraints.

Furthermore, companies seeking to join the CDM pay the auditors' fees, and that's a conflict of interest, according to critics. Miguez says that such payment arrangements were laid down at Marrakech, but agrees that it would be better if the CDM board paid the auditors itself.

"With every new system, there will be pluses and minuses," notes Iyer. "But as the number of projects grows, and as companies have seen actual money coming in, awareness and confidence in the process is also growing."

\section{IN BRIEF}

SOLAR SELL Colorado State University in Fort Collins says that a spin-off company started by one of its professors could employ up to 500 people to make solar panels that will "dramatically reduce" the price of solar power. AVA Solar will make the panels from glass coated with a film of cadmium telluride, a technology developed by Walajabad Sampath, a mechanical engineer at the university. The university claims that the panels will deliver power to the consumer for less than US $\$ 2$ a watt of capacity - about half the cost of currently available alternatives.

PULL TOGETHER Leading drug companies and a group of academic institutions say that they will work together to explore people's genetic susceptibility to the side effects of drugs. The International Serious Adverse Events Consortium, led by Arthur Holder, formerly of Baxter International, is starting off with studies of susceptibility to a skin condition called Stevens-Johnson syndrome and to drug-related liver problems. Pharmaceutical companies hope that genetic tests will eventually become available that will identify patients at risk from taking certain drugs.

BIOFUELS BACKING Amyris Biotechnologies, a company in Emoryville, California, that specializes in designing microorganisms for use in the production of biofuels, has secured $\$ 70$ million in funding from venture-capital firms. A tranche of backers led by Duff Ackerman and Goodrich Ventures in San Francisco, California, have come up with the money. Amyris says that the money will help it to develop fuels such as biogasoline, biodiesel and bio jet fuel, which it hopes to bring to the market by 2010 .

\section{MARKET WATCH}

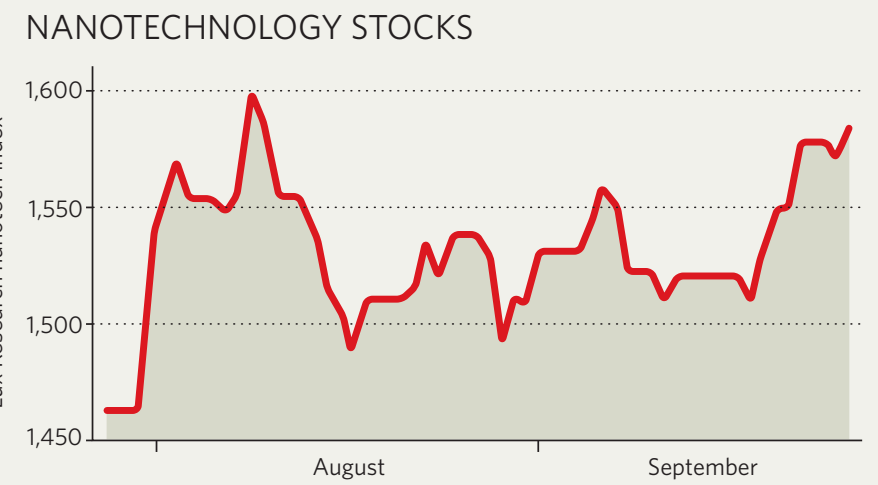

After the general dip that hit global stock markets at the end of July, the value of nanotechnology companies steadied in the past few months, as investors absorbed a mixed bag of financial results.

The Lux Research nanotech index, charted above, measures the performance of a basket of companies that sell nanotechnology products and services as well as some major industrial corporations that make strategic use of them.

There weren't many star performances among the companies over August and September. Peter Hebert, chief executive of Lux Research, the New York consultancy firm that compiles the index, says that Nanophase Technologies Corporation, a relatively long-established nanomaterials firm in Romeoville, Illinois, is trading well, with sales up $75 \%$ from last year. But the market remains unmoved, with its stock stuck at around $\$ 7$ for the past three years.

Flamel Technologies, a drug-delivery company in Vénissieux, France, has gone through a difficult period after losing a deal with the British pharmaceutical giant GlaxoSmithKline. Flamel's stock has fallen steadily from almost $\$ 40$ earlier in the year to less than $\$ 9$ last week.

But according to Hebert, the sector is encouraged by a pending initial public offering on the Nasdaq for stock in Nanosphere, a spin-off company from Northwestern University in Evanston, Illinois. The molecular-diagnostics company is hoping to raise up to $\$ 100$ million from the offering, the date for which is about to be set. "This is one of the first true nanotechnology start-ups to reach the market," Hebert says. "A lot of people will be looking at that - and a number of others could follow."

Colin Macilwain 